\title{
Multi-level Fuzzy Rules-Based Analysis of Virtual Team Performance
}

\author{
Dalia Kriksciuniene and Sandra Strigunaite \\ Department of Informatics, Vilnius University, Muitines 8, LT-44280 Kaunas, Lithuania \\ \{dalia.kriksciuniene, sandra.strigunaite\} @vukhf. It
}

\begin{abstract}
The article presents model for evaluation of virtual team performance based on the intelligent methods of Multi-level fuzzy rules and Fuzzy Signature. The hierarchical system of parameters for virtual team performance evaluation is elaborated by applying expert survey. The aggregated measure of performance of virtual project team is derived from twelve parameters assigned to three categories (team, task and interaction). The experimental research is based on fuzzy analysis of interaction data of virtual teams which worked on implementation of three software solution projects. The research results provide evidence for the feasibility of using the proposed method as the tool for virtual project managers seeking to improve their leadership techniques, and to derive parameters for performance evaluation based on intelligent computing methods.
\end{abstract}

Keywords: E-leadership, virtual team performance evaluation, fuzzy rules, fuzzy signature.

\section{$1 \quad$ Introduction}

Management activities of any project are often distinguished to project administration and leadership. This applies for project teams working in the real or virtual environment. The need for e-leadership in virtual project teams has become increasingly relevant as businesses move toward more non-traditional work [1]. The leadership of virtual work management and coordination is much more complicated not only because of the communication restrictions of the virtual working environment, but also because of inability of the manager to be aware of the moods and informal communication context within the team. Managers in virtual and other "organic contexts" are indeed less able to exercise the same influence [2].

Lee [3] indicates a gap in the body of knowledge while applying situational leadership theory to virtual project management. Konradt and Hoch [4] state that eleadership requires a different type of leadership techniques than the traditional project management.

The differences of conducting real and virtual projects are especially vivid from team member collaboration perspectives. The integration and change of fast developing technologies for project / task management and collaboration processes among team members is challenging for search of effective analytical techniques which could improve insightfulness of a project leader and his ability of adequate 
performance evaluation. Application of intelligent analytic techniques for processing team collaboration records can be used as the effective tool for project managers.

Human interaction management theory (HIM) analyses modelling principles of the human work [5]. It emphasizes that the performance of the project work can be designed not only as the workflow of tasks and processes, but it should take into account the interaction processes among project members as well. The work models based on HIM theory should be designed from the role interaction stance by applying special notation for defining interactions related to the project tasks. By applying main concepts of this theory we research core parameters for virtual teamwork evaluation.

In most cases of observing the ways the project managers evaluate teamwork situations we could state that they apply transcendental and linguistic parameter values, for example "the task is complex" or "the experience is low". The output parameters denoting features and outcomes of the project tasks are imprecise as well. Although all project leaders apply their experience and leadership qualities for making decisions and actions in certain situations, the rules and desciptions of these situations are rather difficult to define. The efforts to define the quantitative values for the input, output parameters of the project work and their interrelationships are rather complicated, though the communication data of the project team members is extensively available from the virtual project environment. The imprecise and ambiguous characteristics of the project work imply that the methods suggested by fuzzy computational methods are appropriate for deriving necessary parameters and rules for analysis. These methods find their application in process analysis- in Fayek and Zhuo [6] the investigation of fuzzy expert system for design performance evaluation is presented.

In this article we propose the method for virtual team performance evaluation by applying methods of multi-level fuzzy rules and fuzzy signature.

The article is organised as follows. In section 2 the virtual team performance parameters are defined and their measurement is suggested by applying expert survey. In section 3 the application of multi-level fuzzy rule and fuzzy signature methods is substantiated for further research. In section 4 the procedures of experimental research for virtual team performance evaluation are explained, the interpretation and insights of the research results are overviewed. In the section 5 we conclude of the outcomes and present key challenges for further research.

\section{Virtual Team Performance Measurement Criteria}

The performance measurement criteria of virtual teamwork were researched by conducting expert survey. Possibility to extract appropriate data from team collaboration environment, definition of evaluation criteria, and their quantitative measurement problems were discussed during survey of fifteen experts. The participants of the discussion were project managers of highest experience and technical consultants of JIRA Agile and JIRA Confluent solutions. The in-depth analysis of this research is presented in [9].

By applying concepts of HIM and situational leadership theories, the survey aimed to discuss the topics: "What criteria can be used for evaluating parameters of three dimensions (task, team and interaction) characterizing project implementation in the virtual environment?" and "How these criteria can be derived from the team 
collaboration data, registered in the virtual environment?". According to the suggestions and insights of the experts, the hierarchical list of measurement criteria was elaborated and refined. The criteria list, their descriptions and data source types for defining their value are presented in Table 1.

Team evaluation criteria are of two types (Table 1):

(1) Parameters that describe team as unit,

(2) Parameters for describing individual team members.

In Table 1, the team evaluation criteria that characterize team as the organizational unit include its size, role variety and hierarchy level. These parameters are important for adequate evaluation, as different task/team settings require respective organisational level. The team evaluation criteria that describe individual members provide compound measures aggregated from individual evaluations of each team member. These criteria include experience and characteristics, which jointly form the team maturity criterion.

Table 1. The criteria list for virtual team performance evaluation

\begin{tabular}{|c|c|c|}
\hline Criteria & Description & Source type \\
\hline \multicolumn{3}{|c|}{ Team evaluation criteria } \\
\hline Size & $\begin{array}{l}\text { Number of performers assigned to the task during whole task } \\
\text { implementation period }\end{array}$ & System / Value \\
\hline Variety & Number of different roles assigned to task & System / Value \\
\hline Experience & Level of team experience & Expert \\
\hline Characteristics & $\begin{array}{l}\text { Cumulative measures of personal characteristics: attitude to } \\
\text { work/task implementation of the performer }\end{array}$ & Expert \\
\hline Hierarchy & $\begin{array}{l}\text { Level of team hierarchy (the rate of high, middle, junior } \\
\text { experience within a particular role) }\end{array}$ & System / Value \\
\hline \multicolumn{3}{|c|}{ Task evaluation criteria } \\
\hline Phase & $\begin{array}{l}\text { Expert judgment /manager evaluation, parameter rate from a } \\
\text { particular interval (beginning, middle or end of a particular } \\
\text { project phase or iteration) }\end{array}$ & Expert / System \\
\hline $\begin{array}{l}\text { Task } \\
\text { intelligence } \\
\text { level }\end{array}$ & $\begin{array}{l}\text { Expert evaluation of the necessity of human driven effort, } \\
\text { necessary to implement particular task }\end{array}$ & Expert \\
\hline Result clarity & $\begin{array}{l}\text { Expert / project team evaluation about quality criteria and } \\
\text { clarity of the expected result }\end{array}$ & Expert \\
\hline \multicolumn{3}{|c|}{ Interaction evaluation criteria } \\
\hline Meeting level & Number of meetings and their type, topic, average duration & \multirow{3}{*}{$\begin{array}{l}\text { System/Compo } \\
\text { und value } \mathrm{f}(\mathrm{t})\end{array}$} \\
\hline $\begin{array}{l}\text { Questioning } \\
\text { level }\end{array}$ & $\begin{array}{l}\text { Number and types of questions sent to team members and } \\
\text { requests for information to team leader and senior members }\end{array}$ & \\
\hline $\begin{array}{l}\text { Information } \\
\text { sharing level }\end{array}$ & $\begin{array}{l}\text { Eagerness of team and individual members to share } \\
\text { information }\end{array}$ & \\
\hline $\begin{array}{l}\text { Punctuality } \\
\text { level }\end{array}$ & Parameter describing team punctuality level & $\begin{array}{l}\text { System / Value } \\
\text { Yes / No set }\end{array}$ \\
\hline
\end{tabular}


Task evaluation criteria are strongly based on project specifics; therefore, they can be evaluated by applying Computations, Compromise, Experts judgement or Inspiration decision processes, suggested in [11]. As not all task implementation circumstances can be known in advance, one of the recommendations of the expert survey was to include parameters denoting task intelligence level and its difficulty. The compound characteristic of task "difficulty" is derived from the phase and result clarity criteria (Table 1). The criteria, which belong to the task category, are designed to show if implementation of particular task needs team with a high experience or high level of team interaction capabilities.

The third group of criteria related to interaction evaluation describes expected interaction activeness level among team members during the specified task implementation period. The evaluation of criteria, denoting questioning and information sharing levels summarize amount of various types of messages, records in blog and wiki areas, exchanged by team members.

The compound evaluation criteria, which describes the meetings held during implementation of particular task, depends on evaluation of questioning and information sharing.

Punctuality shows if the interim or final results of a task are presented on time or are reported to be done within an acceptable time.

All project management experts agreed that possibility to observe communication of team members in virtual surrounding is as much necessary as in real environment. The patterns of team behaviour, characteristics of communication situations can provide important insights about task implementation process.

The possibilities to use virtual communication data for criteria measurement were explored by analysing the collaborative software application ComindWork [10]. In Table 1 it is shown, that the values of the parameters can be set as quantitative values (Value), computed from the appropriate data from project environment (System) or defined by project experts and leadership (Expert). In either case the values of the lowest level criteria have to be quantified.

The hierarchical structure of the criteria set implies that the criteria of higher level can be computed as compound characteristics. The parameter list is designed for characterizing situation of task fulfilment by the project team. The experienced leader of the project management is expected to define the possible outcomes of task fulfilment based on evaluation of input criteria. Three output value descriptions are chosen for further investigation:

(1) Well - if task implementation process is performed well;

(2) Chaos (Delay) - if there is a problem of non-understanding and chaotic communication;

(3) Bad - if work is delayed or stagnated.

Our goal is to present method how to evaluate the hierarchical criteria, to derive rules for defining interrelationships of the input and output criteria, and assign the output values describing task fulfilment situation. The imprecise and expert-based origin of the performance evaluation criteria implies application of fuzzy methods for their further processing. 


\section{$3 \quad$ Multi-level Rule Base Method with Fuzzy Signature Approach}

Multi-level fuzzy rule method and application of fuzzy signatures aggregation techniques was chosen for the design of model for evaluation virtual teamwork performance.

Fuzzy signatures are used for constructing hierarchical structures of fuzzy characteristics. They can be applied for modelling the complex structure of data in a hierarchical manner (bottom up). The Fuzzy signatures can reduce complexity with slightly more complicated aggregation techniques in huge fuzzy structures. Fuzzy signature can be considered as a special kind of multi-dimensional fuzzy data, where some of the dimensions are formed as a variable sub-group and determines features of a higher level parameter or group [12]. This means that instead of assigning a single membership grade to each element $\mathrm{X}$, as it is done when defining original fuzzy sets, a set of quantitative features are assigned to each element $X$ which can have a structure of another nested vector, this way providing additional information about that specific element of the domain. This structure can be continued and finally form a signature with finite depth $m$ [13].

The method of fuzzy signature was introduced by Koczy (1999) [13]. It is the generalization of vector valued fuzzy sets (VVFS). It means, that each element is assigned by matching $A$ to each element $\mathrm{x} \in \mathrm{X}$ or vector component of another VVFS (branch) or atomic value (leaf) [13]. It can be specified as in formula (1):

$$
A: x \rightarrow\left[a_{i}\right]_{i=1}^{k} \equiv \prod_{i=1}^{k} a_{i},
$$

here $\prod$ denotes the Cartesian product, and

$$
a_{i}= \begin{cases}{\left[a_{i j}\right]_{j=1}^{k_{i}}} & ; \text { if branch } \\ {[0,1]} & ; \text { if leaf }\end{cases}
$$

Fuzzy signature can be charted as the nested vector or hierarchical tree structure (see Fig. 1a and Fig.1b)

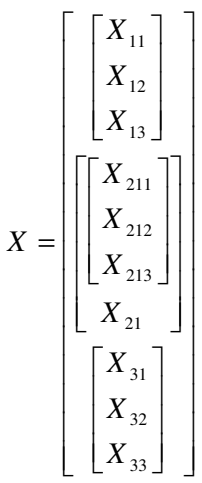

(a) As a vector

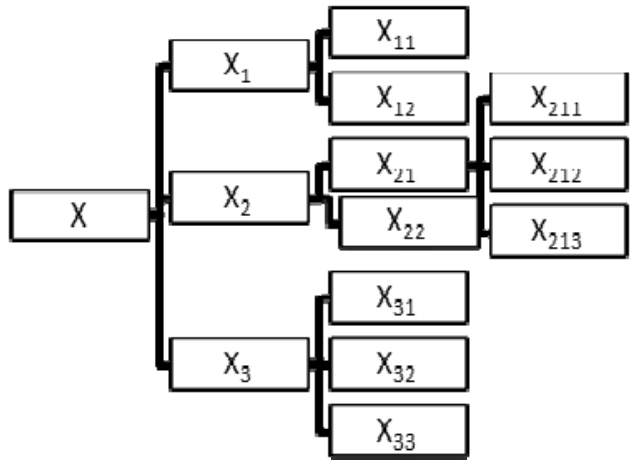

(b) As a tree

Fig. 1. Fuzzy Signature structures 
The whole structure of fuzzy signature looks like a tree graph. The lowest level elements of this fuzzy signature denote leaves, the middle - branches.

In the Fuzzy Signature structure (Fig 1 (b)) leaves $\left[X_{11}, X_{12}\right]$ are sub-group of the higher level compound joint $X_{1}$, the leaves $\left[X_{211}, X_{212}, X_{213}\right]$ form higher level compound $X_{21}$, which compounds $X_{2}$ in a conjunction with $X_{22}$. Therefore $X_{2}$ can be expressed as $\left[\left[X_{211}, X_{212}, X_{213}\right], X_{22}\right]$ or $\left[X_{21}, X_{22}\right]$.

In the highest level of fuzzy signature it can be abstracted as $X=\left[X_{1}, X_{2}, X_{3}\right]$ or as vector showed in Fig. 1 (a). The underlying general concept of fuzzy signature is a nested vector [13].

The connections between higher and lower levels are constructed by fuzzy set aggregations. The most common aggregation operations are the maximum, minimum and arithmetic mean. The possibility to select the method of abstraction allows to modelling particular situations of performance evaluation, where some of the parameters can be assigned different weights or even lose their importance due to specific situations of task fulfilment.

Fuzzy signatures are used for constructing Fuzzy Rules. In general fuzzy rule is described as the following structure: "If $\mathrm{x}$ is $A_{i}$ then $\mathrm{y}$ is $B_{i}$ ", where $A_{i}$ is the rule antecedent and $B_{i}$ is the rule consequent, $\mathrm{x}$ is the observation and $\mathrm{y}$ is the conclusion.

The rule antecedent $A_{i}$ can be a fuzzy signature set or fuzzy signature singleton. The signatures have the same arbitrary structure, and the corresponding aggregation operators are uniform for every rule. The consequent parts of the rules remain fuzzy sets [14].

The method is applied for processing the variables and criteria included to the model characterizing virtual teamwork and its performance.

\section{Analysis of Multi-level Fuzzy Rules Method Application for Virtual Team Performance Situation Evaluation}

\subsection{Hierarchical Evaluation Criteria Structure}

The results of expert survey and analysis of virtual team performance measurement criteria, as presented in section 2, were processed by applying fuzzy signature concept for designing the hierarchical virtual team performance evaluation model. The hierarchical set of criteria is presented in Table 2. The scheme refined by the participants of the survey is arranged in four levels. The lower level criteria have the lowest level of fuzziness and can be assigned values by using interaction data of the virtual space or determined by project leader. Three possible values are selected as situation output.

The criteria of the higher level are computed by applying fuzzy signature method. The hierarchical virtual team performance evaluation scheme is explored by the experimental research, discussed in the following section. 
Table 2. Hierarchical virtual team performance evaluation scheme

\begin{tabular}{|c|c|c|c|}
\hline Input criteria (leaves) & \multicolumn{2}{|c|}{ Middle criteria (branches) } & Output \\
\hline (C121) Result clarity $\{$ Low; High $\}$ & (C12) Tock diffi & \multirow{3}{*}{ (C1) Task } & \multirow{12}{*}{$\begin{array}{c}(\mathbf{C}) \\
\text { Situation } \\
\text { \{Bad; } \\
\text { Chaos; } \\
\text { Well\} }\end{array}$} \\
\hline (C122) Phase \{Low; High\} & 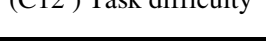 & & \\
\hline \multicolumn{2}{|l|}{ (C11) Task intelligence level \{Low; High $\}$} & & \\
\hline (C222) Characteristics \{Low; High $\}$ & \multirow{2}{*}{ (C22) Maturity level } & \multirow{5}{*}{ (C2) Team } & \\
\hline (C221) Experience $\{$ Low; High $\}$ & & & \\
\hline (C211) Size \{Low; High $\}$ & \multirow{3}{*}{$\begin{array}{l}\text { (C21) Organisational } \\
\text { level }\end{array}$} & & \\
\hline$(\mathrm{C} 212)$ Role variety $\{$ Low; High $\}$ & & & \\
\hline (C213) Hierarchy level \{Low; High $\}$ & & & \\
\hline (C311) Meeting level \{Low; High $\}$ & \multirow{3}{*}{ (C31) Activity level } & \multirow{4}{*}{$\begin{array}{l}\text { (C3) Interaction } \\
\text { level }\end{array}$} & \\
\hline (C312) Questioning level \{Low; High $\}$ & & & \\
\hline $\begin{array}{l}\text { (C313) Information sharing level } \\
\{\text { Low; High }\}\end{array}$ & & & \\
\hline (C32) Punctuality level \{Low; High $\}$ & & & \\
\hline
\end{tabular}

\subsection{Experimental Research Setting}

The goal of the experiment was to test if the suggested parameter hierarchical structures can help to identify task implementation situations.

Table 3. Experimental data description

\begin{tabular}{l|l|l|l}
\hline Parameter & First project & Second project & Third project \\
\hline Duration & 2 year & 6 month & 1 year \\
\hline Phases & 9 & 3 & 6 \\
\hline $\begin{array}{l}\text { Number of team } \\
\text { members }\end{array}$ & $9-12$ & $2-4$ & $12-20$ \\
\hline Hierarchy & High & Low & Middle/High \\
\hline Role variety & Middle / High & Low & Middle / Low \\
\hline $\begin{array}{l}\text { Analysed number of } \\
\text { tasks (work packages) }\end{array}$ & 144 & 48 & 480 \\
\hline Majority of task types & Mix & Intelligent & Difficult/Routine \\
\hline $\begin{array}{l}\text { Majority of task } \\
\text { Situations identified }\end{array}$ & Mix & Well & Chaos \\
\hline $\begin{array}{l}\text { Working style reason of } \\
\text { Main Experience } \\
\text { problems }\end{array}$ & One big group & Individual work & $\begin{array}{l}\text { Working in small / } \\
\text { individual groups }\end{array}$ \\
\hline
\end{tabular}


The data of the experimental research was derived form three IT software implementation projects, where the team members communicated in the virtual space during the most part of the projects. The logs of virtual teamwork collaboration system were used. The team leader had possibility to observe all the communication instances of the team members related to task fulfilment during the project work. All projects had teams with different experience and organizational structures, and different working styles. Brief descriptions of projects are presented in Table 3.

Task was defined as a work package for certain functionality implementation. The shortest tasks lasted from two days, but majority had duration from one to two weeks. If a task was implemented on time then its outcome was marked as Well, if the task was delayed without clear outcome, then it was denoted as Chaos, and if the task planning was changed or redone, then it was marked as Bad. Limitations of the research were related to data evaluation: the virtual communication data could be used for evaluation of small part of parameters, the remaining part were expert evaluations and had high level of uncertainty.

\subsection{Application of Fuzzy Signature and Fuzzy Rules}

Multi-level Fuzzy rule applying Fuzzy Signatures method is suitable for this type data analysis because of the possibility to apply bottom-up fuzzy parameter evaluation and aggregation techniques.

The Fuzzy Signature structure for Hierarchical virtual team performance is presented in formula (4). For parameter aggregation the arithmetic mean was used.

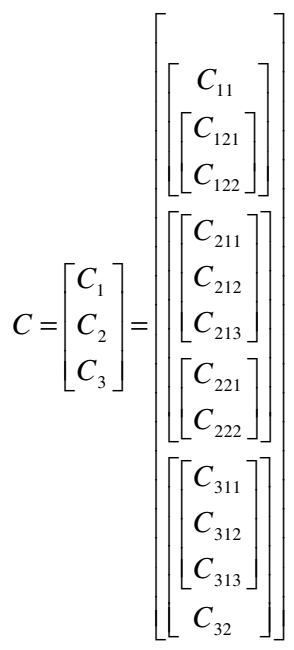

The Fuzzy Signatures for Fuzzy Rule construction is identified by three parameters [(C1)Task, (C2)Team, (C3)Interaction]. Each parameter has several possible value intervals. These parameter value interval ranges and their clarifications are presented in Table 4. 
Table 4. Third level parameter value intervals and their clarifications

\begin{tabular}{|c|c|c|c|}
\hline $\begin{array}{l}\text { Criteria } \\
\text { value name }\end{array}$ & $A b r$ & $\begin{array}{l}\text { Value } \\
\text { range }\end{array}$ & Value get in these circumstances \\
\hline \multicolumn{3}{|l|}{ Team evaluation } & $\begin{array}{l}\text { Formula : } \\
C_{2}=\left(\left(C_{211}, C_{212}, C_{213}\right),\left(C_{221}, C_{222}\right)\right)\end{array}$ \\
\hline Strong team & $\mathrm{H}$ & {$[0.75 ; 1]$} & High level of Organisation $\left(\mathrm{C}_{21}\right)$ and Maturity $\left(\mathrm{C}_{22}\right)$ parameters. \\
\hline $\begin{array}{l}\text { Experienced } \\
\text { team }\end{array}$ & MH & $\begin{array}{l}{[0.65 ; 0.85} \\
]\end{array}$ & $\begin{array}{l}\text { Lower evaluation of Organisation }\left(\mathrm{C}_{21}\right) \text { parameter (then } \\
\text { structure is flat) and High evaluation of Maturity }\left(\mathrm{C}_{22}\right) \text {. }\end{array}$ \\
\hline $\begin{array}{l}\text { Growing } \\
\text { team }\end{array}$ & ML & $\begin{array}{l}{[0.35 ; 0.75} \\
]\end{array}$ & $\begin{array}{l}\text { Lower level of Maturity }\left(\mathrm{C}_{22}\right) \text { and High or Middle level of } \\
\text { Organization }\left(\mathrm{C}_{21}\right)\end{array}$ \\
\hline Weak team & $\mathrm{L}$ & {$[0 ; 0.45]$} & Low level Maturity $\left(\mathrm{C}_{22}\right)$ and Organization $\left(\mathrm{C}_{21}\right)$ \\
\hline \multicolumn{3}{|l|}{ Task evaluation } & $\begin{array}{l}\text { Formula: } \\
C_{1}=\left(C_{11},\left(C_{121}, C_{122}\right)\right)\end{array}$ \\
\hline $\begin{array}{l}\text { Intelligent } \\
\text { task }\end{array}$ & $\mathrm{H}$ & {$[0.65 ; 1]$} & $\begin{array}{l}\text { High evaluation of Intelligence }\left(\mathrm{C}_{11}\right) \text { parameter and } \\
\text { High/Middle evaluation of Difficulty }\left(\mathrm{C}_{12}\right) . \\
\end{array}$ \\
\hline $\begin{array}{l}\text { Difficult } \\
\text { task }\end{array}$ & M & {$[0.4 ; 0.7]$} & $\begin{array}{l}\text { Evaluation of parameter Difficulty is }\left(\mathrm{C}_{12}\right) \text { High/Middle and } \\
\text { Lower evaluation of Intelligence }\left(\mathrm{C}_{11}\right) \text {. }\end{array}$ \\
\hline Routine task & $\mathrm{L}$ & {$[0 ; 0.45]$} & $\begin{array}{l}\text { Task with evaluation of Low is defined as routine and little } \\
\text { intelligence requiring task. This type task can be dedicated to } \\
\text { Growing team. }\end{array}$ \\
\hline \multicolumn{3}{|c|}{ Interaction evaluation } & $\begin{array}{l}\text { Formula: } \\
C_{2}=\left(\left(C_{311}, C_{312}, C_{313}\right), C_{32}\right)\end{array}$ \\
\hline $\begin{array}{l}\text { Very strong } \\
\text { activity }\end{array}$ & $\mathrm{VH}$ & {$[0.75 ; 1]$} & $\begin{array}{l}\text { All parameters: Meeting }\left(\mathrm{C}_{311}\right) \text {, Questioning }\left(\mathrm{C}_{312}\right) \text { and } \\
\text { Information sharing }\left(\mathrm{C}_{313}\right) \text { values are High. }\end{array}$ \\
\hline $\begin{array}{l}\text { Low sharing } \\
\text { of } \\
\text { information }\end{array}$ & $\begin{array}{l}\text { HS } \\
\text { L }\end{array}$ & {$[0.65 ; 0.8]$} & $\begin{array}{l}\text { Then Meeting }\left(\mathrm{C}_{311}\right) \text { and Questioning }\left(\mathrm{C}_{312}\right) \text { are High/Middle } \\
\text { and Information sharing }\left(\mathrm{C}_{313}\right) \text { value is Low. }\end{array}$ \\
\hline $\begin{array}{l}\text { Active and } \\
\text { proper } \\
\text { information } \\
\text { sharing }\end{array}$ & M & {$[0.45 ; 0.7]$} & $\begin{array}{l}\text { All parameters Meeting }\left(\mathrm{C}_{311}\right) \text {, Questioning }\left(\mathrm{C}_{312}\right) \text { and } \\
\text { Information sharing }\left(\mathrm{C}_{313}\right) \text { valued as High/Middle. There is } \\
\text { balance. }\end{array}$ \\
\hline $\begin{array}{l}\text { Low } \\
\text { activity but } \\
\text { strong } \\
\text { information } \\
\text { sharing }\end{array}$ & $\begin{array}{l}\text { LS } \\
\mathrm{H}\end{array}$ & {$[0.25 ; 0.5]$} & $\begin{array}{l}\text { Then Meeting }\left(\mathrm{C}_{311}\right) \text {, Questioning }\left(\mathrm{C}_{312}\right) \text { parameters are } \\
\text { evaluated as Middle/Low and Information sharing }\left(\mathrm{C}_{313}\right) \text { values } \\
\text { are High. }\end{array}$ \\
\hline $\begin{array}{l}\text { Very low } \\
\text { activity }\end{array}$ & VL & {$[0 ; 0.3]$} & $\begin{array}{l}\text { All parameters: Meeting }\left(\mathrm{C}_{311}\right) \text {, Questioning }\left(\mathrm{C}_{312}\right) \text { and } \\
\text { Information sharing }\left(\mathrm{C}_{313}\right) \text { values are Low. }\end{array}$ \\
\hline
\end{tabular}

Output values is parameter Situation $(\mathrm{C})$ with value intervals defined as $\{\mathrm{Bad}\}$, $\{$ Chaos $\}$ or $\{$ Well $\}$. The ranges of each value interval is $[0 ; 0.3]-\mathrm{Bad},[0.3 ; 0.7]-$ Chaos and $[0.7 ; 1]-$ Well. 
By using Team/Task/Interaction parameter interval ranges sixty different parameter combinations (fuzzy rules) are constructed and assigned to one of the possible Outcomes.

Fuzzy rules are constructed by using MatLab software application. The results are plotted as the three-dimensional diagrams where the interrelationships of three categories- team, task and situation- are further interpreted.

The insights are provided by analysing the fuzzy rules derived of interrelationships of input variables plotted on $\mathrm{X}$ and $\mathrm{Y}$-axes of the diagram and output variable plotted on Z-axis.

The insights on Situation outcomes by analysing Team and Task input variables are derived from the surface diagram presented in Fig.2. The patterns of various combinations are presented by using categories of fuzzy values form Table 4. Five Situation patterns are identified:

- P1-W1 Strong Team [0.8;1] reaches situation outcome which belong to the value area Well [ $>0.8]$ almost with any type of task.

- $\quad$ P2-W2 Experienced team in a range [0.7;0.8] with task type Difficult $[0.4 ; 0.6]$ reaches situation Well [0.8]. Noticeable that with Routine task [0;0.4] and Intelligent task $[0.7 ; 1]$ evaluation of situation is lower.

- P3-W3 Growing Team [0.4;0.5] can perform task that requires lower level of intelligence (routine type), as it was assigned Situation value [0.75] for the Task simple/routine [0;0.3].

- P4-C1 Growing team $[0.4 ; 0.5]$ and Difficult/Intelligent $[0.4 ; 1]$ task lead to situation assigned to Chaos [0.4;0.5].

- $\quad$ P5-B1 Weak Team [0;0.3] with difficult/intelligent [0.4;1] task lead to Situation value in a range $[0 ; 0.3]$ that means Bad. Even if low intelligence tasks can be dedicated for this team type, good situation can't be expected.

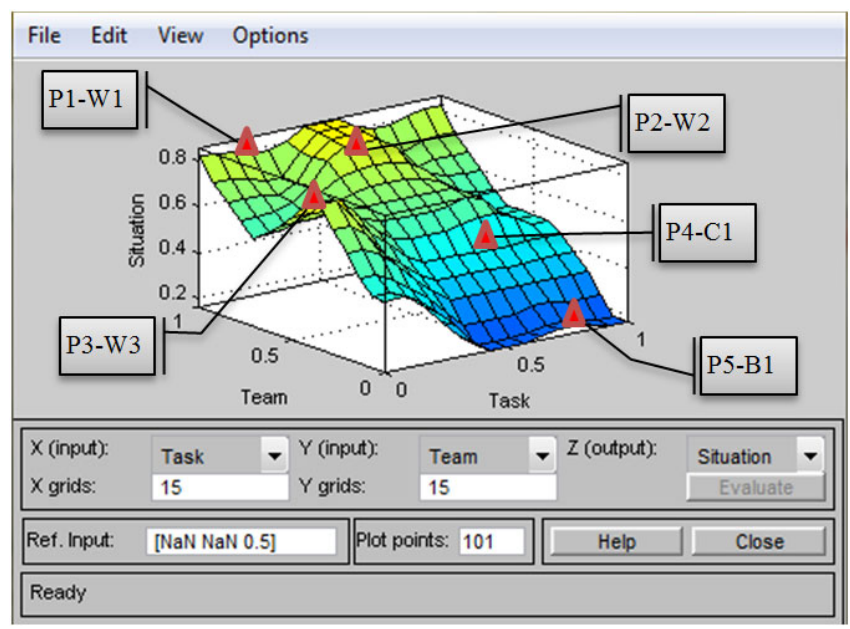

Fig. 2. Team and Task surface diagram 
Insights on Situation outcome by analysing Task and Interaction combination showed that mostly chaotic situations were identified. This indicates the Team parameter has the highest influence on final situation outcome. By analysing Team-Task combination results presented in the surface diagram (Fig.3) the following Situation patterns were identified:

- P6-W4 then task is Intelligent [0.8;1] and Interaction rate is High $[0.9 ; 1]$ Situation is evaluated as Well [0.8]. In is the best possible situation.

- $\quad$ P7-W5 if task belongs to Routine type task range [0;0.3] and Interaction rate is Low [0;0.2] the situation assigned value of Well [0.7];

- P8-C2 Task is Difficult [0.4;0.8] and Interaction belongs to range [0.4;1] then Situation value is Chaos [0.5;0.6]. Analysing these type situations is possible to state that value of parameter Team plays the decisive role for defining situation outcome.

- $\quad$ P9-C3 Interaction range is in Middle [0.5] and Task is strongly intelligent $[0.9 ; 1]$ then situation is assigned to Chaos $[0.4 ; 0.5]$.

- P10-C4 Task routine/Difficult [0;0.2] and Interaction denotes very low level of information sharing [0.3], in this case the sudden fall of situation assessment is noticed.

- P11-C5 Task Routine [0;0.3] and Interaction is High [0.9;1] then Situation is defined as strong Chaos [0.3] almost Bad;

- P12-B2 Task Difficult [0.3;0.6] and Interaction is Low [0.3], borderline situation assessment for Bad and Chaos ranges [0.3].

- P13-B3 Interaction Low [0;0.2] and Task is Intelligent [0.9;1] then situation is defined as completely Bad [0;0.2].

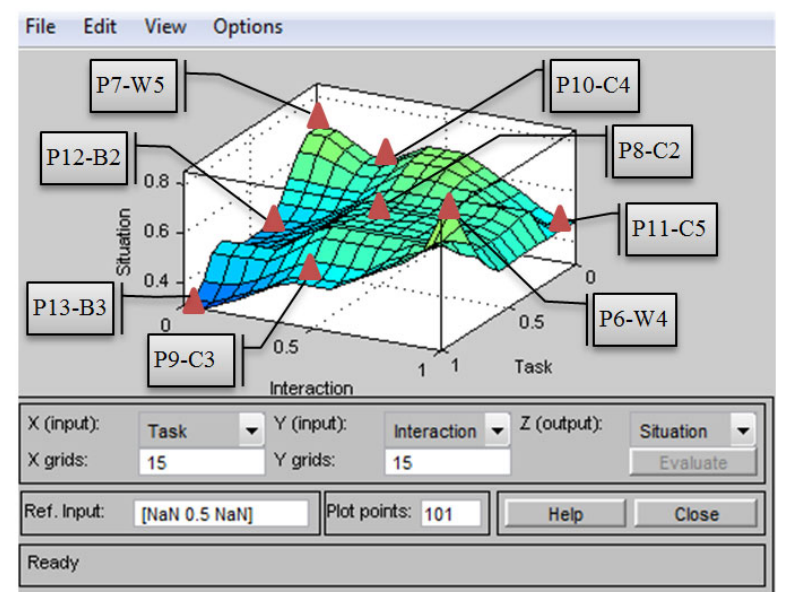

Fig. 3. Task and Interaction surface diagram

Some additional insights of Situation outcomes are derived by analysing Interaction and Team combinations. Four strong patterns are identified (Fig.4 ). 


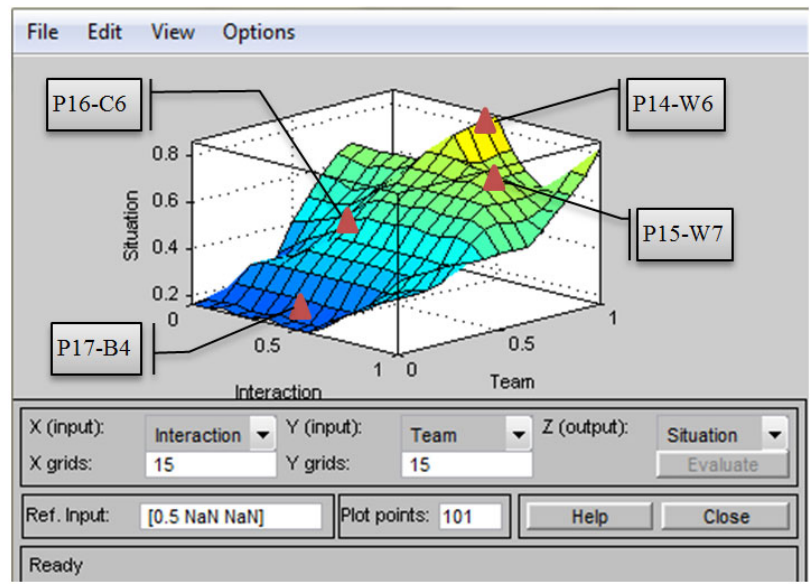

Fig. 4. Interaction and Team surface diagram

- P14-W6 situation within the range of $[0.7 ; 0.8]$ is evaluated as Well by the combination of input: rate of Interactions is middle [0.5] and Team type is Strong [0.8;1]. If Team is strong [0.95;1] and Interaction rate is High [0.95;1] situation leads to the result Well too.

- P15-W7 Team is experienced [0.7;0.8] then situation is identified as Well [0.7] with any value of the Interaction parameter.

- P16-C6 Interaction rate is Middle/High [0.4;0.9] and Team parameter belongs to range Growing [0.4], then situation is defined as Chaotic $[0.4 ; 0.6]$.

- P17-B4 Interaction rate is Low $[0 ; 0.3]$ and Team is Weak $[0 ; 0.2]$, then situation is assigned to $\mathrm{Bad}[0 ; 0.3]$.

The results presented in surface diagrams and describes as insights for project evaluation can be used for forecasting of the situation outcome and for defining strategies aimed to strengthen particular parameters in order to avoid project risk. The advantage of the presented method is its ability to derive values of the situation evaluation parameters which have the highest level of abstraction and risk from the values of lowest level parameters which can be easier evaluated by even less experienced project leaders or computed from the interaction data of virtual communication space. The methods of fuzzy signature and fuzzy rules solve the problem of the fuzziness of parameters values and their hierarchical structure.

The aims of further research include refinement of criteria evaluation methods and implementation of fuzzy signature based model to the virtual teamwork environment.

\section{Conclusions and Further Research}

The analysis of scientific research related to project leadership techniques and their application to virtual teamwork analysis revealed lack of effective performance evaluation methods. The methods based on subjective judgement and direct observations of team members fail in the virtual environments. 
The proposed method for evaluation of virtual team performance aimed to refine the system of parameters and apply computational method for their quantitative evaluation.

The expert survey was applied for designing model consisting of twelve fuzzy parameters arranged in the hierarchical structure that characterize dimensions of Team, Task and Interaction, leading to evaluation of virtual team work performance situation. The list of parameters and can be refined by further research.

The fuzziness of the input and output variables and their interrelationships led to applying the methods of fuzzy rules. The hierarchical structure of the parameter set and the "bottom-up" approach used for evaluation of higher level criteria implied using the methods and fuzzy signature. The criteria enlisted in the lower level of the suggested model can be not only evaluated by experts or project leaders, but by deriving their values from the interaction and log data stored in the virtual teamwork environments. The fuzzy rule set and their interpretation was designed by analysis of three dimensions: Task, Team and Situation. The applied principles can be refined for creation of expert database for project and task evaluation purposes with higher accuracy of recognizing problematic or chaotic virtual team work performance situations.

The insights and interpretations of the research results can be useful for virtual teamwork evaluation and to reduce risk of direct evaluation of project situation by the inexperienced project leaders without taking into account the underlying lower level criteria.

\section{References}

1. Den Hartog, D.N., Keegan, A.E., Verburg, R.M.: Limits to leadership in virtual contexts. The Electronic Journal for Virtual Organizations and Networks 9 (2007); Special Issue: The Limits of Virtual Work

2. Cascio, W.F., Shurygailo, S.: E-Leadership and virtual teams. Engineering Management Review 36(1), 79-79 (2008)

3. Lee, M.R.: E-leadership for project managers: A study of situational leadership and virtual project success, Ph.D. Dissertation, Capella University, USA (2010) ISBN 9781124067209

4. Konradt, U., Hoch, J.: A work roles and leadership functions of managers in virtual teams. International Journal of E-Collaboration, 16-35 (2007)

5. Harrison-Broninski, K.: Human Interactions: The Heart and Soul of Business Process Management. Meghan-Kiffer Press (2005) ISBN 0929652444

6. Fayek, A.R., Zhuo, S.: A fuzzy expert system for design performance prediction and evaluation. Canadian Journal of Civil Engineering (2005)

7. Jarvelin, K., Wilson, T.D.: On conceptual models for information seeking and retrieval research. Information Research an International Electronic Journal 9(1) (2003)

8. Chen, S.C., Lee, A.H.I.: Performance Measurement of SMEs' Employees by Fuzzy Multicriteria Decision Theory. In: 2010 International Symposium on Computer, Communication, Control and Automation (2010) 
9. Kriksciuniene, D., Strigunaite, S.: Virtual Team Tasks Performance Evaluation Based on Multi-level Fuzzy Comprehensive method. In: The Third International Conference on Future Computational Technologies and Applications (in press, 2011)

10. Comind Work, Manage people online, http: / / www. comindwork. com

11. PMBOK. A guide to the project management body of knowledge: PMBOK guide, $3 \mathrm{rd}$ edn., p. 403. Four Campus Boulevard, Pennsylvania (2004) ISBN 1-930699-45-X

12. Mendis, B.S.U.: Fuzzy Signatures: Hierarchical Fuzzy Systems and Applications. Ph.D Dissertation. Australian National University, Australia (2008)

13. Koczy, L.T., Vamos, T., Biro, G.: Fuzzy Signatures. In: Proceedings of Eurofuse-SIC 1999, Hungary, pp. 210-217 (1999)

14. Tamas, K., Koczy, L.T.: Inference in Fuzzy Signature Based Model. Series Intelligentia Computatorica 1(3), 61-82 (2008) 